\title{
Are there any further modalities for prediction of subclinical volume overload in advanced stages of chronic kidney disease?
}

\author{
Aber Halim Baki ${ }^{1}$, Cherry Reda Kamel ${ }^{1}$, Hazem Mansour ${ }^{2}$ \\ ${ }^{1}$ Department of Internal Medicine and Nephrology, Faculty of Medicine, Ain Shams University, Cairo, Egypt \\ ${ }^{2}$ Department of Cardiology, Faculty of Medicine, Ain Shams University, Cairo, Egypt
}

Background: Subclinical volume overload in chronic kidney disease (CKD) patient represents a debatable issue. Although many tools were used to detect volume overload in such patients, many non-specific results were due to presence of comorbidities. Bioimpedance spectroscopy is an objective fluid status assessment method, which is shown superior to classical methods in many studies. Combining some of these tools may improve their accuracy and specificity. Inferior vena cava collapsibility index (IVCCI) with brain natriuretic peptide (BNP) can be combined for more specific volume assessment. This study was performed to assess the usage of combined IVCCl and BNP levels in CKD patients to predict subclinical volume overload.

Methods: One hundred and ten patients with CKD (stages 4 and 5) not on dialysis and having normal left ventricular systolic function were included in this study. Exclusion criteria were: (1) patients with other causes of raised BNP than volume overload and (2) patients on diuretics. A complete medical history was obtained, and thorough examination and laboratory tests were performed for all included patients. IVCCI and BNP serum levels were evaluated. The patients who exhibited an overhydration (OH)/extracellular water (ECW) ratio of $>15 \%$ were considered to have volume overload.

Results: Twenty-six patients (23.6\%) had subclinical hypervolemia as diagnosed by $\mathrm{OH} / \mathrm{ECW}$ ratio of $>15 \%$. IVCCl $\leq 38 \%$ had higher diagnostic performance than BNP $\geq 24 \mathrm{pg} / \mathrm{mL}$. Combining both IVCCI $\leq 38 \%$ and $\mathrm{BNP} \geq 24 \mathrm{pg} / \mathrm{mL}$ increased the specificity and positive predictive value for detection of subclinical hypervolemia.

Conclusion: Combined elevated BNP level and decreased IVCCI are more precise tools for subclinical volume overload detection in CKD patients.

Keywords: B-type natriuretic peptide, Bioelectric impedance, Chronic kidney disease, Echocardiography, Fluid overload, Inferior vena cava collapsibility index

Received: July 29, 2020; Revised: November 7, 2020; Accepted: November 29, 2020

Editor: Sejoong Kim, Seoul National University, Seongnam, Republic of Korea

Correspondence: Aber Halim Baki

Department of Internal Medicine and Nephrology, Faculty of Medicine, Ain Shams University, 16 Al Badiya Street of Althawra Misr elgedida, Cairo 11371, Egypt. E-mail: aberhalim@med.asu.edu.eg

ORCID: https://orcid.org/0000-0002-2374-8412

Copyright () 2021 by The Korean Society of Nephrology

() This is an Open Access article distributed under the terms of the Creative Commons Attribution Non-Commercial and No Derivatives License (http:// creativecommons.org/licenses/by-nc-nd/4.0/) which permits unrestricted non-commercial use, distribution of the material without any modifications, and reproduction in any medium, provided the original works properly cited. 


\section{Introduction}

Volume overload is an essential prognostic parameter associated with compromised oxygenation, end-organ damage, prolonged hospital stays, morbidity, and mortality in chronic kidney disease (CKD) and end-stage renal disease (ESRD) patients. Volume overload manifests as left ventricular (LV) hypertrophy, hypertension, fluid shift into the third space, and increased arterial stiffness [1-6].

The use of bioimpedance spectroscopy (BIS) to detect volume overload is a novel tool that has been increasingly used due to its being simple, inexpensive, and noninvasive [7-9]. BIS is thought to be an objective fluid status assessment method more sensitive and accurate than classical methods such as BP and weight monitoring $[10,11]$. Whole-body BIS has now been widely used in clinical settings for the management of ESRD patients [12-14]. New research should critically evaluate the benefit of these BIS approaches in CKD patient care.

However, BIS is expensive-125 US dollars per test. This dollar value is based on the 2017 Medicare reimbursement amount [15]. Also, BIS devices are not widely available in most hemodialysis units and nephrology clinics in Egypt and other developing countries for financial reasons. Therefore, the need for the use of readily available laboratory or radiological markers to assess fluid overload (FO) in CKD patients exists.

Natriuretic peptides have been used for volume overload detection even in the absence of clinically diagnosed heart failure. Brain natriuretic peptide (BNP) levels are increased in patients with renal insufficiency [16-19]. In volume overload patients, an increase in natriuretic peptide levels was suggested to be a result of either volume expansion or LV hypertrophy or failure [20]. Although the use of natriuretic peptides for fluid status assessment is a subject of debate $[16,20]$, numerous studies have shown a direct association between these biomarkers and hypervolemia [21,22].

Echocardiography, a widely available bedside test, is essential for assessing cardiac function in CKD patients. The inferior vena cava (IVC) acts as a reservoir for blood within the venous system, and changes in IVC collapsibility or distensibility correlate with the body's fluid status. IVC collapsibility index (IVCCI) is the proportion of IVC collapse occurring with respiration and can be calculated by IVCCI $=\left[\mathrm{IVC}_{\max }-\mathrm{IVC}_{\min }\right] / \mathrm{IVC}_{\max }[23]$. Recent studies have demonstrated the high sensitivity and specificity of ultrasonographic evaluation of IVC collapse, and further investigations are indicated for determining the effectiveness of ultrasonography. Although many factors may affect IVC collapse measurement, ultrasonography can be used for the assessment of fluid responsiveness when bioimpedance is not available [24].

Therefore, use of the combination of IVCCI and BNP, rather than depending on a single method, is important for proper assessment of the fluid status in CKD, especially when BIS is not available or too costly. The aim of this work was to assess the combined usage of IVCCI and BNP levels as markers for concealed volume overload in patients with advanced CKD and normal LV systolic function.

\section{Methods}

A cross-sectional study was performed using data from 110 patients collected from January 2019 to October 2019 from multicenter outpatient clinics (OPCs): OPCs of Ain Shams University, Cairo Specialized Hospital, and Ain Shams University Specialized Hospital in Cairo, Egypt. The study is exempt from ethical committee approval as the authors provided full funding of the project that included only noninvasive procedures.

\section{Inclusion criteria}

Patients with CKD (stages 4 and 5) not on dialysis and having normal LV systolic function ejection fraction (> 55\%) were included.

\section{Exclusion criteria}

(a) Patients with congestive heart failure (CHF) or clinical evidence of volume overload

(b) Patients with pulmonary hypertension

(c) Patients with significant structural valve lesions

(d) Patients on diuretics, angiotensin converting enzyme inhibitors, and angiotensin-receptor blockers

We collected demographic and clinical data. These data included age, sex, height, weight, body mass index (BMI), blood pressure, presence of diabetes, antihypertensive medication use, and laboratory investigations. These 
laboratory investigations included complete blood test; serum creatinine level; urea and uric acid level; albumin level; serum $\mathrm{K}$, sodium (Na), and calcium levels; and serum BNP level.

Body composition monitor (BCM; Fresenius Medical Care D GmbH, Homburg, Germany) performed BIS for this study. BIS precisely measured the fluid status and body composition (extracellular water [ECW], overhydration $[\mathrm{OH}]$, fat tissue mass, and lean tissue mass [LTM]). We equated fluid to $\mathrm{OH} / \mathrm{ECW}$ ratio and used this ratio to define subclinical volume overload. The patients who exhibited an $\mathrm{OH} / \mathrm{ECW}$ ratio > $15 \%$ were considered to be hypervolemic $[25,26]$.

\section{Echocardiography}

We measured LV dimensions and function and IVCCI and identified any valvular abnormalities. IVC was assessed through the subcostal window; the transducer was placed just inferior to the xiphoid process along the midline to obtain a long axis image of the IVC. The IVCCI is expressed as the difference between IVC maximum diameter (on expiration) and IVC minimum diameter (on inspiration) divided by the IVC maximum diameter; $\left(\mathrm{IVC}_{\max }-\mathrm{IVC}_{\min }\right) /$ $\mathrm{IVC}_{\max } \times 100$.

\section{Statistical methods}

\section{Sample size justification}

We used the results of Baki et al. [27] who demonstrated that the sensitivity and specificity of BNP were $71.0 \% \%$ and $77.8 \%$, respectively, and the frequency of hypervolemia was $77.5 \%$. We assumed the null hypothesis for sensitivity and specificity as $50.0 \%$ each, a power $=0.80$ and an $\alpha=0.05$. We used Power Analysis and Sample Size (PASS) system, 11th version (Hintze [28]) to determine that the minimum sample size for a cross-sectional study using these parameters is 101 cases. We included 110 cases for better precision.

The collected data was coded, tabulated, and statistically analyzed using Microsoft Excel 2007 (Microsoft, Redmond, WA, USA) and IBM SPSS version 22.0 (IBM Corp., Armonk, NY, USA).

Descriptive statistics were performed on quantitative data and included range minimum and maximum and mean \pm standard deviation for quantitative normally distributed data. Number and percentage are provided for qualitative data.

Inferential analyses were conducted on quantitative variables using the Shapiro-Wilk test for normality testing; an independent $t$ test was conducted in cases of two independent groups with normally distributed data. For qualitative data, inferential analyses for independent variables was performed using the chi-square test for differences between proportions. Correlations were obtained using Pearson correlation for numerical normally distributed data. Receiver operating characteristic curve was used to evaluate the performance of different tests that differentiated between certain groups. A linear regression model was used to discover independent factors involving $\mathrm{OH} / \mathrm{ECW}$ ratio. A p-value of $<0.050$ was considered to be significant.

Diagnostic characteristics were calculated as:

Sensitivity $=($ true positive test $/$ total positive golden $) \times 100$ Specificity $=($ true negative test $/$ total negative golden $) \times$ 100

Diagnostic accuracy $=([$ true positive test + true negative test $] /$ total cases $) \times 100$

Youden's index $=$ sensitivity + specificity -1

Predictive positive value $=($ true positive test $/$ total positive test) $\times 100$

Predictive negative value $=($ true negative test $/$ total negative test $) \times 100$

$\mathrm{LR}+=$ sensitivity $/(1-$ specificity $)$

LR- = (1 - sensitivity/specificity $)$

$\mathrm{LR}=\mathrm{LR}+/ \mathrm{LR}-$

\section{Results}

The mean age of the study group was $40.2 \pm 9.7$ years (Table 1 ). The study group's mean BMI was $24.5 \pm 2.5 \mathrm{~kg} / \mathrm{m}^{2}$. Fortytwo patients $(38.2 \%)$ were diabetics and $51(46.4 \%)$ were hypertensive. Thirty-eight patients (34.5\%) were smokers. The study group's mean glomerular filtration rate (GFR) was $23.4 \pm 5.6 \mathrm{~mL} / \mathrm{min} / 1.73 \mathrm{~m}^{2}$ and mean serum creatinine level was $4.1 \pm 0.8 \mathrm{mg} / \mathrm{dL}$.

Patients with hypervolemia had significantly higher BMI, serum $\mathrm{Na}$, and BNP level as well as highly significantly lower IVCCI. However, there was no significant difference between hypervolemic and normovolemic patients regarding other demographic and laboratory findings in the study population (Table 1). 
Table 1. Demographic, laboratory, echocardiographic, and bioimpedance findings

\begin{tabular}{|c|c|c|c|c|}
\hline Variable & All cases & Hypervolemia & Normovolemia & $p$-value \\
\hline No. of patients & 110 & 26 & 84 & \\
\hline Age (yr) & $40.2 \pm 9.7$ & $39.8 \pm 9.3$ & $40.4 \pm 9.8$ & $0.793^{\mathrm{a}}$ \\
\hline \multicolumn{5}{|l|}{ Sex } \\
\hline Male & $70(63.6)$ & $17(65.4)$ & $53(63.1)$ & $0.832^{b}$ \\
\hline Female & $40(36.4)$ & $9(34.6)$ & 31 (36.9) & \\
\hline Body mass index $\left(\mathrm{kg} / \mathrm{m}^{2}\right)$ & $24.5 \pm 2.5$ & $25.5 \pm 2.7$ & $24.2 \pm 2.4$ & $0.019^{a, *}$ \\
\hline Duration of renal disease (yr) & $6.9 \pm 2.3$ & $6.2 \pm 1.9$ & $7.1 \pm 2.4$ & $0.087^{\mathrm{a}}$ \\
\hline Hypertension & $38(34.5)$ & $12(46.2)$ & $26(31.0)$ & $0.154^{b}$ \\
\hline Diabetes mellitus & $29(26.4)$ & $9(34.6)$ & $20(23.8)$ & $0.274^{b}$ \\
\hline Smoking & $38(34.5)$ & $10(38.5)$ & 28 (33.3) & $0.631^{\mathrm{b}}$ \\
\hline Creatinine (mg/dL) & $4.1 \pm 0.8$ & $4.3 \pm 0.8$ & $4.1 \pm 0.8$ & $0.248^{\mathrm{a}}$ \\
\hline Urea $(\mathrm{mg} / \mathrm{mL})$ & $94.6 \pm 19.7$ & $95.9 \pm 22.1$ & $94.2 \pm 19.0$ & $0.698^{\mathrm{a}}$ \\
\hline Uric acid (mg/mL) & $4.4 \pm 1.5$ & $4.4 \pm 1.6$ & $4.5 \pm 1.5$ & $0.765^{\mathrm{a}}$ \\
\hline Albumin (g/dL) & $3.9 \pm 0.3$ & $3.8 \pm 0.3$ & $3.9 \pm 0.3$ & $0.079^{\mathrm{a}}$ \\
\hline $\mathrm{sNa}(\mathrm{mmol} / \mathrm{L})$ & $144.5 \pm 8.1$ & $147.5 \pm 6.0$ & $143.5 \pm 8.5$ & $0.031^{a, *}$ \\
\hline Calcium (mg/dL) & $7.6 \pm 0.6$ & $7.6 \pm 0.6$ & $7.5 \pm 0.6$ & $0.383^{a}$ \\
\hline $\mathrm{sK}(\mathrm{mmol} / \mathrm{L})$ & $4.8 \pm 0.5$ & $4.9 \pm 0.5$ & $4.8 \pm 0.5$ & $0.278^{\mathrm{a}}$ \\
\hline BNP (pg/mL) & $25.3 \pm 9.4$ & $30.2 \pm 11.6$ & $23.7 \pm 8.1$ & $0.002^{a, *}$ \\
\hline IVCCI (\%) & $37.4 \pm 11.6$ & $26.3 \pm 7.2$ & $40.9 \pm 10.5$ & $<0.001^{a, *}$ \\
\hline $\mathrm{OH} / \mathrm{ECW}$ ratio & $10.2 \pm 6.5$ & $19.4 \pm 3.1$ & $7.3 \pm 4.3$ & $<0.001^{a, *}$ \\
\hline $\mathrm{SBP}(\mathrm{mmHg})$ & $143.7 \pm 3.2$ & $144.7 \pm 3.0$ & $143.4 \pm 3.3$ & 0.090 \\
\hline DBP (mmHg) & $81.1 \pm 2.0$ & $81.7 \pm 1.8$ & $80.9 \pm 2.0$ & 0.092 \\
\hline MBP (mmHg) & $102.0 \pm 2.3$ & $102.7 \pm 2.2$ & $101.8 \pm 2.3$ & 0.078 \\
\hline
\end{tabular}

Data are expressed as number only, mean \pm standard deviation, or number (\%).

BNP, brain natriuretic peptide; DBP, diastolic blood pressure; ECW, extracellular water ratio; IVCCI, inferior vena cava compressibility index; MBP, mean blood pressure; $\mathrm{OH}$, overhydration; SBP, systolic blood pressure; sK, serum potassium; sNa, serum sodium.

andependent t test, ${ }^{\mathrm{b}}$ chi-square test.

${ }^{*} \mathrm{p}<0.050$.

There were significant positive correlations between FO (OH/ECW ratio) and BMI, serum Na, BNP, systolic blood pressure, diastolic blood pressure, and mean blood pressure as well as a significant negative correlation with IVCCI. Furthermore, no significant correlations were established between $\mathrm{OH} / \mathrm{ECW}$ ratio and GFR, creatinine, urea, uric acid, albumin, calcium, and potassium (Table 2).

The linear regression model for diagnostic factors for FO showed that, among the studied variables, only lower IVCCI and higher BNP were significantly associated with higher $\mathrm{OH} / \mathrm{ECW}$ ratio (Table 3). Multivariable linear regression analysis confirmed the significant correlations between FO and both BNP and IVCCI after adjustment for confounding variables (Table 4 ).

Our data showed that, regarding diagnosis of hypervolemia, BNP ( $\geq 24 \mathrm{pg} / \mathrm{mL})$ had a significantly low diagnostic performance while IVCCI $(\leq 38 \%)$ had a significantly moderate diagnostic performance. Despite the correlation between fluid
Table 2. Correlations of fluid overload as indicated by the overhydration to extracellular water ratio

\begin{tabular}{lcc}
\hline Factor & $r$ & $p$-value \\
\hline Age & 0.006 & 0.954 \\
Body mass index & 0.205 & $0.032^{*}$ \\
Duration & -0.124 & 0.195 \\
Creatinine & 0.063 & 0.513 \\
Urea & 0.010 & 0.915 \\
Uric acid & -0.004 & 0.970 \\
Albumin & -0.168 & 0.079 \\
sNa & 0.214 & $0.024^{*}$ \\
Calcium & 0.064 & 0.508 \\
sK & 0.078 & 0.416 \\
BNP & 0.262 & $0.006^{*}$ \\
IVCCl & -0.434 & $<0.001^{*}$ \\
SBP & 0.264 & $0.005^{*}$ \\
DBP & 0.240 & $0.011^{*}$ \\
MBP & 0.261 & $0.006^{*}$ \\
\hline
\end{tabular}

BNP, brain natriuretic peptide; DBP, diastolic blood pressure; IVCCI, inferior vena cava compressibility index; MBP, mean blood pressure; SBP, systolic blood pressure; sK, serum potassium; sNa, serum sodium. $* \mathrm{p}<0.050$. 
Table 3. Linear regression analysis between fluid overload $(\mathrm{OH} /$ ECW ratio) and IVCCI and BNP

\begin{tabular}{lccccc}
\hline Factor & $\beta$ & SE & p-value & $95 \% \mathrm{Cl}$ & $\mathrm{R}^{2}$ \\
\hline Constant & 14.999 & 2.489 & $<0.001^{*}$ & $10.065-19.932$ & 0.237 \\
IVCCI & -0.232 & 0.048 & $<0.001^{*}$ & -0.327 to -0.138 & \\
BNP & 0.153 & 0.059 & $0.010^{*}$ & $0.037-0.270$ &
\end{tabular}

$\beta$, regression coefficient; $\mathrm{BNP}$, brain natriuretic peptide; $\mathrm{Cl}$, confidence interval; ECW, extracellular water ratio; IVCCI, inferior vena cava compressibility index; $\mathrm{OH}$, overhydration; $\mathrm{R}^{2}$, coefficient of determination; $\mathrm{SE}$, standard error.

$* p<0.050$.

Table 4. Multivariable linear regression analysis for different predictors of fluid overload after adjustment for different confounders

\begin{tabular}{lrcccc}
\hline Factor & \multicolumn{1}{c}{$\beta$} & SE & $p$-value & $95 \% \mathrm{Cl}$ & $\mathrm{R}^{2}$ \\
\hline Constant & 15.325 & 2.312 & $<0.001^{*}$ & $10.365-20.693$ & 0.242 \\
BMI & 2.315 & 1.823 & 0.613 & $1.625-4.635$ & \\
sNa & 0.621 & 0.456 & 0.082 & $0.423-0.925$ & \\
BNP & 0.143 & 0.061 & $0.009^{*}$ & $0.052-0.289$ & \\
IVCCI & -0.228 & 0.031 & $<0.001^{*}$ & -0.342 to -0.125 & \\
SBP & 2.325 & 1.986 & 0.514 & $1.325-2.863$ & \\
DBP & 1.965 & 1.532 & 0.364 & $1.625-3.654$ & \\
MBP & 3.876 & 2.634 & 0.072 & $2.346-4.874$ & \\
\hline
\end{tabular}

$\beta$, regression coefficient; $\mathrm{BMI}$, body mass index; BNP, brain natriuretic peptide; $\mathrm{Cl}$, confidence interval; DBP, diastolic blood pressure; IVCCI, inferior vena cava collapsibility index; MBP, mean blood pressure; $\mathrm{R}^{2}$, coefficient of determination; SBP, systolic blood pressure; SE, standard error; sNa, serum sodium.

$* \mathrm{p}<0.050$.

volume (OH/ECW ratio) and both BMI and $\mathrm{Na}$, neither had a significant diagnostic performance for volume overload (Table 5, Fig. 1).

BNP had a sensitivity of $76.9 \%$ and a specificity of $58.3 \%$; those values for IVCCI were $96.2 \%$ and $63.1 \%$, respectively (Table 6). However, if the patient had both IVCCI $\leq 38 \%$ and $\mathrm{BNP} \geq 24 \mathrm{pg} / \mathrm{mL}$ concurrently, the specificity and positive predictive value increased to $86.9 \%$ and $63.3 \%$, respectively, while the sensitivity and negative predictive value decreased to $73.1 \%$ and $91.3 \%$, respectively. If the patient had either IVCCI $\leq 38 \%$ or BNP $\geq 24 \mathrm{pg} / \mathrm{mL}$, perfect sensitivity and negative predictive value $(100 \%)$ were achieved at the expense of decreased specificity and positive predictive value (Table 6).

\section{Discussion}

Routine evaluation of hydration includes monitoring of
Table 5. Performance of BMI, sNa, BNP, and IVCCl in diagnosing hypervolemia

\begin{tabular}{lccccc}
\hline Factor & AUC & SE & p-value & $95 \% \mathrm{Cl}$ & Cutoff \\
\hline BMI & 0.606 & 0.063 & 0.102 & $0.483-0.730$ & - \\
SNa & 0.628 & 0.057 & 0.051 & $0.515-0.741$ & - \\
BNP & 0.660 & 0.065 & $0.014^{*}$ & $0.533-0.786$ & $\geq 24.0 \mathrm{pg} / \mathrm{mL}$ \\
IVCCl & 0.880 & 0.034 & $<0.001 *$ & $0.815-0.946$ & $\leq 38.0 \%$ \\
\hline
\end{tabular}

$\mathrm{AUC}$, area under curve; BMI, body mass index; BNP, brain natriuretic peptide; $\mathrm{Cl}$, confidence interval; IVCCl, inferior vena cava collapsibility index; SE, standard error; sNa, serum sodium. ${ }^{*} \mathrm{p}<0.050$.

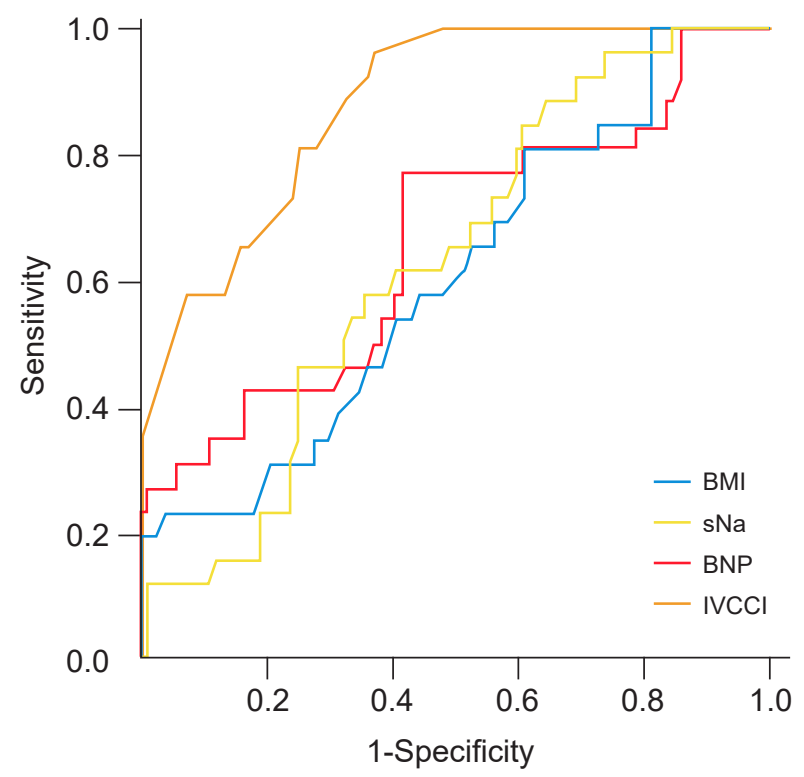

Figure 1. Receiver operating characteristics curves for BMI, sNa, $\mathrm{BNP}$, and IVCCI in diagnosing hypervolemia.

$\mathrm{BMI}$, body mass index; sNa, serum sodium; BNP, brain natriuretic peptide; IVCCI, inferior vena cava collapsibility index.

body weight and blood pressure changes that are not reliably determined by fluid volume. Edema is not usually detectable until interstitial fluid volume increases $30 \%$ over normal levels (4-5 kg gain in body weight), and severe dehydration can occur before appearance of clinical signs. Thus, traditional indicators of over- and under-hydration in patients with renal disease are insensitive and inadequate [15] .

Volume status assessment of advanced CKD (stages 4 and 5) patients not on dialysis is crucial. Clinical sign assessments are also essential even though a significant number of patients have subclinical volume overload with no evident clinical signs. For example, dependent edema is occasionally challenging to identify, especially in nonambulatory patients. Other physical measurements, 
Table 6. Diagnostic characteristics of BNP and IVCCI cutoff points in hypervolemia

\begin{tabular}{|c|c|c|c|c|}
\hline Characteristic & $\mathrm{BNP} \geq 24.0 \mathrm{pg} / \mathrm{mL}$ & $\mathrm{IVCCl} \leq 38.0 \%$ & $\begin{array}{c}\mathrm{BNP} \geq 22.0 \mathrm{pg} / \mathrm{mL} \\
\text { and } \\
\mathrm{IVCCl} \leq 38.0 \%\end{array}$ & $\begin{array}{c}\mathrm{BNP} \geq 24.0 \mathrm{pg} / \mathrm{mL} \\
\text { or } \\
\mathrm{IVCCl} \leq 38.0 \%\end{array}$ \\
\hline Sensitivity (\%) & 76.9 & 96.2 & 73.1 & 100 \\
\hline Specificity (\%) & 58.3 & 63.1 & 86.9 & 34.5 \\
\hline Diagnostic accuracy (\%) & 62.7 & 70.9 & 83.6 & 50.0 \\
\hline Youden's index (\%) & 35.3 & 59.2 & 60.0 & 34.5 \\
\hline Positive predictive value (\%) & 36.4 & 44.6 & 63.3 & 32.1 \\
\hline Negative predictive value (\%) & 89.1 & 98.1 & 91.3 & 100 \\
\hline Positive likelihood ratio & 1.85 & 2.61 & 5.58 & 1.53 \\
\hline Negative likelihood ratio & 0.40 & 0.06 & 0.31 & 0 \\
\hline Diagnostic odds ratio & 4.67 & 42.74 & 18.01 & Infinity \\
\hline
\end{tabular}

BNP, brain natriuretic peptide; IVCCI, inferior vena cava collapsibility index.

such as changes in body weight or blood pressure, are influenced by many issues other than volume load status. Early detection of this problem can prevent deleterious sequelae [24].

BIS is one of the modifications of bioimpedance analysis. Chamney et al. [29] developed a "three-compartment body model", which differentiates between normally hydrated LTM, adipose tissue mass, and a virtual $\mathrm{OH}$ compartment. This model assumes a fixed hydration of LTM and adipose tissue mass that results in the calculation of a "normohydration weight." The $\mathrm{OH}$ compartment is calculated as the difference between the measured and the expected ECW. "Expected" is the difference found in the normally functioning population; the 10th to 90th percentile $(-1.1 \mathrm{~L}$ and $+1.1 \mathrm{~L})$ of the normal population is considered to represent a normovolemic situation. Literature definitions of FO vary between a value of $>1.1 \mathrm{~L}$ and $2.5 \mathrm{~L}$ (or an $\mathrm{OH} / \mathrm{ECW}$ ratio above $7 \%$ or $15 \%$ ). Fluid depletion is defined as an FO level below $-1.1 \mathrm{~L}$ [30].

The BIS method relies on the assumption that lowfrequency current flows through the extracellular fluid (ECF) and high-frequency current penetrates ECF and intracellular fluid. These assumptions are open to criticism largely because of their derivation from in vitro studies of cells suspended in fluid; cell-cell interfaces that occur in tissues are ignored. These calculations are performed with software provided by the manufacturers of the different BIS instruments and are subject to change. Significant errors can occur in the estimation of total body water (TBW, $2 \mathrm{~L}$ ) and ECW $(\sim 1 \mathrm{~L})$ in individuals with increased adiposity. A proposed remedy to this limitation is the use of BMI as a proxy for adiposity. A limitation of the use of BMI as a surrogate for body fat content is the lack of sensitivity of BMI to reliably differentiate the body composition (body fat and muscle mass) of an individual, healthy or ill. A consistent observation is the wide limits of agreement between the impedance and reference methods that cautions against the use of these methods for individual assessment of fluid volumes [31].

Using BNP level to assess volume overload is relatively inexpensive; however, due to relatively low specificity, more studies are needed to clarify the effectiveness of BNP level in assessing volume overload in CKD patients [27].

IVCCI is the proportion that the IVC collapses with respiration and can be calculated by IVCCI $=\left(\mathrm{IVC}_{\max }-\right.$ $\left.\mathrm{IVC}_{\min }\right) / \mathrm{IVC}_{\max }$ [23]. Changes in collapsibility or distensibility correlate with the body's fluid status. However, IVCCI's validity is questionable since IVC diameter does not only depend on volume status and may be affected by respiration, right heart function, and intraabdominal or intrathoracic pressure changes. Also, IVC imaging can be challenging especially in patients with large body habitus, excessive bowel gas, or large amounts of intrathoracic air [32,33]. A recent study showed that, after a certain threshold, IVCCI is considerably specific and sensitive for observing volume expansion [32].

Therefore, the combination of IVCCI and BNP, rather than depending on a single method, is important for proper assessment of the fluid status in CKD. This combination improves the specificity of the individual tests and may provide a guide to optimize medical management, especially when BIS is not available or too costly. Combining these tools 
may improve the accuracy and specificity of both and justifies using both rather than each one individually. Therefore, in this current study we evaluated the combination of these two easy and readily accessible tools. Our study population consisted of 110 patients with CKD in whom we detected volume overload before being evident clinically by measuring both IVCCI and BNP levels.

We assessed volume overload in the 110 cases by measuring $\mathrm{OH} / \mathrm{ECW}$ ratio that equated to $\mathrm{FO}$. We found that 26 patients (23.6\%) had subclinical hypervolemia $(\mathrm{OH} / \mathrm{ECW}>15 \%)$. Data on subclinical volume overload in CKD patients is scarce. A few studies evaluated subclinical volume overload only in dialysis patients. Although there was paucity of data about the percentage of subclinical volume overload in CKD patients, few studies evaluated this issue; however, they included only patients on dialysis. One study of them which evaluated 100 hemodialysis patients, showed close results to ours; with the percentage of FO (29\%) using BIS despite being clinically euvolemic. FO was defined by a relative tissue hydration, i.e., $\mathrm{OH} / \mathrm{ECW}>15 \%$, which was the similar parameter used in our study to define hypervolemia [25].

Concerning the demographic and laboratory data, we found no significant differences between hypervolemic and euvolemic patients regarding age, sex, and presence of hypertension or diabetes. These results agreed with Antlanger et al. [34] who reported no significant sex and age differences in cases of FO.

Hung et al's study [35] findings of data from 338 patients partially disagreed with our results. That group demonstrated a significant correlation between hypervolemia and diabetes mellitus. These conflicting results may be attributed to the larger sample size and a higher percentage of diabetics in that study. However, normo- and hypervolemic groups demonstrated significant differences; higher BMI, serum $\mathrm{Na}$, BNP level, and lower IVCCI were present in the hypervolemic group.

Hypernatremia in subclinical hypervolemic CKD patients, although not commonly seen in patients with clinical volume overload, can be explained. Some patients, particularly those in late stages of CKD were prescribed sodium bicarbonate for treatment of metabolic acidosis leading to hypernatremia. This resulted from osmotic diuresis caused by elevated serum urea, impaired renal concentrating capacity, or nephron loss. Impaired angiotensin II production, which may contribute directly to the impaired thirst mechanism, or excessive water restriction may also be involved [36-38].

Another mechanism may be the use of loop diuretics that interfere with medullary hypertonicity with resultant electrolyte-free water loss from collecting ducts, but the use of diuretics was one of our exclusion criteria.

Similar to the Hung et al.s study [35], we demonstrated significant correlations between hypervolemia and serum Na and BNP levels. As expected, in our study hypervolemia had an important correlation with BMI since excessive body fluids accumulate in the extracellular compartment. A study conducted by Kwan et al. [39] had results consistent with ours. In that study, BMI had a significant correlation with $\mathrm{OH}(\mathrm{r}=0.376, \mathrm{p}<0.001)$.

Our data showed a highly significant negative correlation between hypervolemia and IVCCI $(\mathrm{p}<0.001)$. Barbier et al. [32] showed that, after a certain threshold, IVCCI was highly specific and sensitive for demonstrating volume expansion. Some other studies evaluated this and determined that its accuracy is unproven as IVC diameter is affected by factors other than volume status [33-40].

Allinovi et al. [41] performed fluid assessments on 13 children on dialysis (eight on peritoneal dialysis and five on hemodialysis) with a median age of 4.0 years (range, $0.8-14.0$ years). Their results disagreed with our data. The negative correlation between IVCCI and FO was not significant in their study. These conflicting results may be related to many factors; their study consisted of a small number of young patients and had a single-center design that lacked a robust gold standard measurement of FO.

Regarding BNP as a tool for volume overload detection, our study showed that there was a significant correlation between BNP level and hypervolemia $(p=0.002)$. BNP is useful for the evaluation of ventricular dysfunction in patients with various cardiac diseases. However, its diagnostic value has been considered to be limited in patients with chronic renal failure (CRF) because renal dysfunction may affect BNP levels. Takami et al.'s findings [42] support that plasma BNP level is a reliable marker of LV overload, even in patients with CRF not on dialysis. Also, a high BNP level ( $\geq 150 \mathrm{pg} / \mathrm{mL}$ ) may have powerful predictive potential for heart failure in these patients. These results also agreed with those of Bongartz et al. [43] who reported that high plasma BNP concentrations were associated with volume overload in CKD patients.

Our results demonstrated a cutoff value for BNP's 
usefulness in diagnosing FO ( $\geq 24 \mathrm{pg} / \mathrm{mL})$. However, no data for determination of a BNP level cutoff point for detecting subclinical volume overload in CKD patients not undergoing dialysis are available. Further studies are required to resolve this important issue. However, a study on 40 chronic dialysis patients suggested that a BNP level cutoff value of $17.65 \mathrm{pg} /$ $\mathrm{mL}$ can be used to diagnose volume overload [31]. A cohort study of 348 consecutive patients evaluated the role of B-type natriuretic peptide in diagnosing acute decompensated heart failure in CKD patients. In the patients with heart failure and preserved left ventricular ejection fraction in CKD stages 3 and $4, \mathrm{BNP}<155 \mathrm{pg} / \mathrm{mL}$ was sufficient to rule out acute decompensated heart failure [44].

Our results showed an IVCCI ratio cutoff value of $\leq 38 \%$ for diagnosing FO in CKD patients. However, there were no previous data determining the cutoff value of IVCCI, IVCCI sensitivity, and IVCCI specificity to assess concealed volume overload in CKD patients. Some studies did evaluate IVCCI values in hemodialysis patients. In a study with 22 patients in whom dry weight was determined on clinical grounds, only six had a correct dry weight according to IVC indices [44]. Another study on 40 patients on dialysis to assess volume overload in CRF determined that volume status was categorized as either hypervolemia if IVCCI was $<40 \%$ or hypovolemia if IVCCI $>75 \%$ [45].

Our study found a sensitivity of $76.9 \%$ and a specificity of $58.3 \%$ for BNP and values of $96.2 \%$ and $63.1 \%$, respectively, for IVCCI in the diagnosis of $\mathrm{OH}$ in $\mathrm{CKD}$. In a 2013 prospective study, Anderson et al. [46] explored the accuracy of IVCCI, which was more specific than sensitive in diagnosing CHF, and BNP, which was highly specific. Concerning the concept of the study that combined two modalities to detect subclinical volume overload in CKD patients, there was no previous data for comparison. Our results showed that, for diagnosing hypervolemia, BNP $(\geq 24 \mathrm{pg} / \mathrm{mL})$ had a significantly low diagnostic performance, and IVCCI $(\leq 38 \%)$ had a significantly moderate diagnostic performance. Moreover, the specificity and positive predictive value increased, but the sensitivity and negative predictive value decreased, with the concurrent use of IVCCI and BNP. However, if the case had any IVCCI or BNP, perfect sensitivity and negative predictive value were achieved but at the expense of decreased specificity and positive predictive value.

One of the limitations of this study is that we used only $\mathrm{OH} / \mathrm{ECW}$ as the reference value for volume overload; comparisons of BNP and IVCCI using multiple reference values including ECW/ICW and ECW/TBW may have been more informative.

While IVCCI showed high sensitivity and specificity, measuring BIS with devices such as BCM is easier for assessing FO. This is due to the limited availability of expert echocardiologists in dialysis centers.

Using BIS as reference, we proved that combining IVCCI with a cutoff value of $\leq 38 \%$ and BNP with cutoff value of $\geq 24$ $\mathrm{pg} / \mathrm{mL}$ provides an accurate alternative to BIS for detection of subclinical volume overload in predialysis CKD patients. Further studies with a larger sample size are needed to evaluate the clinical impact of these findings on patient outcomes and mortality.

\section{Conflicts of interest}

All authors have no conflicts of interest to declare.

\section{Acknowledgments}

We acknowledge Dr. Hazem Elhariry for his statistical analysis, and Dr. Bishoy Tanagho for his help in paper submission.

\section{Authors' contributions}

\section{Conceptualization: AHB}

Data curation: AHB, HM

Formal analysis: CRK

Investigation: $\mathrm{AHB}, \mathrm{HM}$

Methodology: AHB, HM

Project administration: AHB

Visualization: AHB

Writing-original draft: AHB, HM

Writing-review \& editing: AHB, CRK

All authors read and approved the final manuscript.

\section{ORCID}

Aber Halim Baki, https://orcid.org/0000-0002-2374-8412 Cherry Reda Kamel, https://orcid.org/0000-0001-9698-0303 Hazem Mansour, https://orcid.org/0000-0002-5366-3698 


\section{References}

1. Arikan AA, Zappitelli M, Goldstein SL, Naipaul A, Jefferson LS, Loftis LL. Fluid overload is associated with impaired oxygenation and morbidity in critically ill children. Pediatr Crit Care Med 2012;13:253-258.

2. Hassinger AB, Wald EL, Goodman DM. Early postoperative fluid overload precedes acute kidney injury and is associated with higher morbidity in pediatric cardiac surgery patients. Pediatr Crit Care Med 2014;15:131-138.

3. Magee G, Zbrozek A. Fluid overload is associated with increases in length of stay and hospital costs: pooled analysis of data from more than 600 US hospitals. Clinicoecon Outcomes Res 2013;5:289-296.

4. Vaara ST, Korhonen AM, Kaukonen KM, et al. Fluid overload is associated with an increased risk for 90-day mortality in critically ill patients with renal replacement therapy: data from the prospective FINNAKI study. Crit Care 2012;16:R197.

5. Mees EJ. Volaemia and blood pressure in renal failure: have old truths been forgotten? Nephrol Dial Transplant 1995;10:12971298.

6. Zoccali C, Torino C, Tripepi R, et al. Pulmonary congestion predicts cardiac events and mortality in ESRD. J Am Soc Nephrol 2013;24:639646.

7. Onofriescu M, Hogas S, Voroneanu L, et al. Bioimpedanceguided fluid management in maintenance hemodialysis: a pilot randomized controlled trial. Am J Kidney Dis 2014;64:111-118.

8. Earthman C, Traughber D, Dobratz J, Howell W. Bioimpedance spectroscopy for clinical assessment of fluid distribution and body cell mass. Nutr Clin Pract 2007;22:389-405.

9. Jaffrin MY, Morel H. Body fluid volumes measurements by impedance: a review of bioimpedance spectroscopy (BIS) and bioimpedance analysis (BIA) methods. Med Eng Phys 2008;30:1257-1269.

10. Wabel P, Chamney P, Moissl U, Jirka T. Importance of wholebody bioimpedance spectroscopy for the management of fluid balance. Blood Purif 2009;27:75-80.

11. Dekker MJ, Marcelli D, Canaud BJ, et al. Impact of fluid status and inflammation and their interaction on survival: a study in an international hemodialysis patient cohort. Kidney Int 2017; 91:1214-1223.

12. Tsai YC, Chiu YW, Tsai JC, et al. Association of fluid overload with cardiovascular morbidity and all-cause mortality in stages 4 and 5 CKD. Clin J Am Soc Nephrol 2015;10:39-46.

13. Oei EL, Fan SL. Practical aspects of volume control in chronic kidney disease using whole body bioimpedance. Blood Purif 2015;39:32-36.

14. Chamney PW, Krämer M, Rode C, Kleinekofort W, Wizemann V. A new technique for establishing dry weight in hemodialysis patients via whole body bioimpedance. Kidney Int 2002;61:22502258.

15. Whitworth PW. Bioimpedance spectroscopy can help prevent clinical lymphedema. Oncol Nurs News 2018;12:May 12.

16. Rascher W, Tulassay T, Lang RE. Atrial natriuretic peptide in plasma of volume-overloaded children with chronic renal failure. Lancet 1985;2:303-305.

17. Mueller C, Laule-Kilian K, Scholer A, et al. B-type natriuretic peptide for acute dyspnea in patients with kidney disease: insights from a randomized comparison. Kidney Int 2005;67: 278-284.

18. McCullough PA, Duc P, Omland T, et al. B-type natriuretic peptide and renal function in the diagnosis of heart failure: an analysis from the Breathing Not Properly Multinational Study. Am J Kidney Dis 2003;41:571-579.

19. Cataliotti A, Malatino LS, Jougasaki M, et al. Circulating natriuretic peptide concentrations in patients with end-stage renal disease: role of brain natriuretic peptide as a biomarker for ventricular remodeling. Mayo Clin Proc 2001;76:1111-1119.

20. Agarwal R. B-type natriuretic peptide is not a volume marker among patients on hemodialysis. Nephrol Dial Transplant 2013;28:3082-3089.

21. Fagugli RM, Vecchi L, Valente F, Santirosi P, Laviola MM. Comparison between oscillometric and auscultatory methods of ambulatory blood pressure measurement in hemodialysis patients. Clin Nephrol 2002;57:283-288.

22. Sivalingam M, Vilar E, Mathavakkannan S, Farrington K. The role of natriuretic peptides in volume assessment and mortality prediction in Haemodialysis patients. BMC Nephrol 2015;16:218.

23. Kircher BJ, Himelman RB, Schiller NB. Noninvasive estimation of right atrial pressure from the inspiratory collapse of the inferior vena cava. Am J Cardiol 1990;66:493-496.

24. Ekinci C, Karabork M, Siriopol D, Dincer N, Covic A, Kanbay M. Effects of volume overload and current techniques for the assessment of fluid status in patients with renal disease. Blood Purif 2018;46:34-47.

25. Merhametsiz O, Oguz EG, Yayar O, Bektan B, Canbakan B, Ayli D. Bioimpedance spectroscopy method to determine hypervolemia in maintenance hemodialysis patients. Hippokratia 2015;19:324-331.

26. Wizemann V, Wabel P, Chamney P, et al. The mortality risk 
of overhydration in haemodialysis patients. Nephrol Dial Transplant 2009;24:1574-1579.

27. Baki AH, Mohab A, Reda C, Morttada A. A cut off value for brain natriuretic peptide indicating volume overload in hemodialysis patients. J Kidney 2017;3:1000151.

28. Hintze J. Power analysis and sample size system (PASS 11). Kaysville (UT): NCSS, LLC; 2011.

29. Chamney PW, Wabel P, Moissl UM, et al. A whole-body model to distinguish excess fluid from the hydration of major body tissues. Am J Clin Nutr 2007;85:80-89.

30. van der Sande FM, van de Wal-Visscher ER, Stuard S, Moissl U, Kooman JP. Using bioimpedance spectroscopy to assess volume status in dialysis patients. Blood Purif 2020;49:178-184.

31. Piccoli A. Estimation of fluid volumes in hemodialysis patients: comparing bioimpedance with isotopic and dilution methods. Kidney Int 2014;85:738-741.

32. Barbier C, Loubières Y, Schmit C, et al. Respiratory changes in inferior vena cava diameter are helpful in predicting fluid responsiveness in ventilated septic patients. Intensive Care Med 2004;30:1740-1746.

33. Nagdev AD, Merchant RC, Tirado-Gonzalez A, Sisson CA, Murphy MC. Emergency department bedside ultrasonographic measurement of the caval index for noninvasive determination of low central venous pressure. Ann Emerg Med 2010;55:290295.

34. Antlanger M, Hecking M, Haidinger M, et al. Fluid overload in hemodialysis patients: a cross-sectional study to determine its association with cardiac biomarkers and nutritional status. BMC Nephrol 2013;14:266.

35. Hung SC, Lai YS, Kuo KL, Tarng DC. Volume overload and adverse outcomes in chronic kidney disease: clinical observational and animal studies. J Am Heart Assoc 2015;4:e001918.

36. Popli S, Tzamaloukas AH, Ing TS. Osmotic diuresis-induced hypernatremia: better explained by solute-free water clearance or electrolyte-free water clearance? Int Urol Nephrol 2014;46:207210.
37. Sam R, Feizi I. Understanding hypernatremia. Am J Nephrol 2012;36:97-104.

38. Lewis JL. MSD manual, Endocrine and metabolic disorders: hypernatremia. Kenilworth (NJ): Merck Sharp \& Dohme Corp., c2021 [cited 2020 Apr 1]. Available from: https://www. msdmanuals.com/professional/endocrine-and-metabolicdisorders/electrolyte-disorders/hypernatremia.

39. Kwan BC, Szeto CC, Chow KM, et al. Bioimpedance spectroscopy for the detection of fluid overload in Chinese peritoneal dialysis patients. Perit Dial Int 2014;34:409-416.

40. Voroneanu L, Cusai C, Hogas S, et al. The relationship between chronic volume overload and elevated blood pressure in hemodialysis patients: use of bioimpedance provides a different perspective from echocardiography and biomarker methodologies. Int Urol Nephrol 2010;42:789-797.

41. Allinovi M, Saleem MA, Burgess O, Armstrong C, Hayes W. Finding covert fluid: methods for detecting volume overload in children on dialysis. Pediatr Nephrol 2016;31:2327-2335.

42. Takami Y, Horio T, Iwashima Y, et al. Diagnostic and prognostic value of plasma brain natriuretic peptide in non-dialysisdependent CRF. Am J Kidney Dis 2004;44:420-428.

43. Bongartz LG, Cramer MJ, Doevendans PA, Joles JA, Braam B. The severe cardiorenal syndrome: 'Guyton revisited'. Eur Heart J 2005;26:11-17.

44. Kadri AN, Kaw R, Al-Khadra Y, et al. The role of B-type natriuretic peptide in diagnosing acute decompensated heart failure in chronic kidney disease patients. Arch Med Sci 2018;14:10031009.

45. Horejs J, Ort J, Němecek K, Straková M. Echography of the inferior vena cava is a simple and reliable tool for estimation of 'dry weight' in haemodialysis patients. Nephrol Dial Transplant 1990;5:238.

46. Anderson KL, Jenq KY, Fields JM, Panebianco NL, Dean AJ. Diagnosing heart failure among acutely dyspneic patients with cardiac, inferior vena cava, and lung ultrasonography. Am J Emerg Med 2013;31:1208-1214. 